\title{
Sistem Informasi Administrasi Membership Pada Pusat Kebugaran Gorilla Gym Jakarta
}

\author{
Humisar Hasugian', Dela Renca ${ }^{2}$, Ikhsan Rosandi ${ }^{3}$, Muhamad Irvan ${ }^{4}$ \\ 1,2,3,4Program Studi Sistem Informasi, Fakultas Teknologi Informasi, Universitas Budi Luhur \\ 1,jl. Ciledug Raya Petukangan Utara, Jakarta Selatan, 021-5853753 \\ e-mail: 1humisar.hasugian@budiluhur.ac.id, ${ }^{2}$ dela.renca@budiluhur.ac.id, \\ 3ikhsan.rosandi@budiluhur.ac.id, ${ }^{4}$ muhamad.irvan@budiluhur.ac.id
}

\begin{abstract}
One of the characteristics of a community in a big city is the desire to live a healthy life, one of them is exercising by visiting a fitness center that has complete sports facilities and adequate equipment. with the increasing interest of the community to exercise the obstacles faced by fitness center providers are the complexity of handling membership, managing difficult training schedules and the limited information available regarding the management of a fitness center. to overcome these obstacles the author designed a membership administration information system at the fitness center by using the Agile Development methodology so that the system designed to be completed quickly and changes that often occur can be addressed immediately, this study uses a unified modeling language (UML) to design and document the system. As for the software used for system design is PHP web programming so that it can be accessed from anywhere and anytime with database management using MySql. So it is expected that the results of this study are membership fitness administration information system that is expected to help the manager in facilitating membership administration.
\end{abstract}

Keywords: administration membership, fitness center, agile development methodology, training schedule.

Abstrak-Salah satu karakteristik dari masyarakat di kota besar adalah adanya keinginan untuk hidup sehat salah satunya berolahraga dengan mengunjungi pusat kebugaran yang mempunyai fasilitas olahraga yang lengkap dan alat yang memadai. dengan semakin banyaknya minat masyarakat untuk berolahraga kendala yang dihadapi oleh penyedia pusat kebugaran adalah rumitnya penanganan membership, pengaturan jadwal latihan yang sulit serta terbatasnya informasi yang tersedia terkait pengelolaan pusat kebugaran. untuk mengatasi kendala tersebut penulis merancang sistem informasi administrasi membership pada pusat kebugaran dengan menggunakan metodologi Agile Development agar sistem yang dirancang cepat selesai dan perubahan yang sering terjadi dapat segera diatasi, penelitian ini menggunakan unified modelling language (UML) untuk merancang dan mendokumentasi sistem. adapun software yang digunakan untuk perancangan sistem adalah pemrograman web PHP agar bisa diakses dari mana sajan dan kapan saja dengan pengelolaan database menggunakan MySql. Sehingga diharapkan hasil dari penelitian ini adalah sistem informasi administrasi membership pusat kebugaran yang diharapkan dapat membantu pihak pengelola dalam mempermudah administrasi membership.

Kata kunci: administrasi membership, pusat kebugaran, agile development metodology, jadwal latihan.

\section{PENDAHULUAN}

Salah satu karakteristik dari masyarakat di kota besar adalah adanya keinginan untuk hidup sehat salah satunya berolahraga dengan mengunjungi pusat 
kebugaran yang mempunyai fasilitas olahraga yang lengkap dan alat yang memadai. Adapun masalah yang sering terjadi pada saat pelayanan administrasi membership antara lain proses pembuatan laporan pendapatan bulanan lama karena harus melihat data transaksi selama periode tertentu, proses pendaftaran membership masih menggunakan kertas sehingga menjadi tidak efektif dan efisien, penulisan nama dan nomor id dalam kartu member masih tulis tangan sehingga tulisan tersebut bisa hilang atau kurang terbaca, Sering terjadi kesalahan dalam mengatur jadwal antara Member dan Traineer Sehingga jadwal menjadi bertentangan mengakibatkan bentroknya jadwal Traineer dan member. Penelitian ini bertujuan untuk membantu pengelola pusat kebugaran dalam hal administrasi membership dengan merancang sistem informasi menggunakan perangkat lunak vb.net dan database mysql, sehingga diharapkan dapat mempermudah dalam penajian laporan, meminimalisasi terjadinya kesalahan penulisan nama dan id pada kartu member, menghindari penumpukan penjadwalan antara member satu dan member lain dalam program personal traineer, membantu mengurangi akibat global warming karena penggunaan kertas yang berlebihan dan mempermudah pemilik perusahaan untuk melihat perkembangan latihan di pusat kebugaran. Adapun penelitian sebelumnya yang sudah pernah dilakukan terkait judul penelitian ini adalah : Rancang Bangun Sistem Informasi Fitness Berbasis Web dan SMS Gateway pada Rajawali Fitness Pekanbaru, oleh Herry Erwanto dan Siti Monalisa, yang diterbitkan pada Jurnal Sains, Teknologi dan Industri, Vol. 14, No. 1, Desember 2016, pp.72 - 78, dengan no ISSN 1693-2390 print/ISSN 2407-0939 online, pada Rajawali Fitness penyimpanan data member masih menggunakan kertas sehingga penyimpanan data member tidak efisien, proses keterlambatan mengingatkan member untuk memperpanjang masa aktifnya, tidak adanya media informasi penjualan suplemen dan alat-alat fitness, pimpinan dalam melihat laporan data member maupun laporan transaksi masih manual. Serta absensi pengunjung untuk media monitoring tidak ada. Tujuannya adalah mengusulkan sistem informasi yang dapat membantu dalam meningkatkan kinerja tempat fitnes. Perancangan menggunakan teknik Object Oriented Analysis Design dan Tools Unified Modelling Language. Sedangkan dalam penerapan sistem, menggunakan bahasa pemograman PHP dan database MySQL. Penelitian ini menggunakan metode waterfall sebagai metode pengembangan sistem.[1]

Penelitian berikutnya berjudul Perancangan Sistem Informasi Membership PT. Gold Gym, oleh Adi Widodo, yang diterbitkan pada Jurnal IPSIKOM Vol. 3 No. 1 Juni 2015, dengan No ISSN : 2338-4093, Untuk mempermudah proses pendaftaran, diperlukan sistem yang dapat melakukan otomatisasi dalam sistem registrasi anggota, instruktur dan jadwal yang tergabung dalam sebuah basis data. Supaya para pengguna sistem mendapatkan informasi yang diinginkan secara cepat dan akurat. Oleh Sebab itu, dibuat sebuah perancangan sistem informasi membership berbasis desktop agar dapat diakses member baru. Pembuatan sistem informasi ini menggunakan bahasa pemrograman $\mathrm{C \#}$, basis data Mysql. Pembuatan sistem informasi ini menggunakan normalisasi terhadap tabel - tabel dalam basis data dan penggambaran logika sistem dengan menggunakan DFD. Pengujian Perancangan Sistem Informasi Membership Berbasis Desktop dilakukan dengan mencoba setiap fungsi yang ada pada sistem informasi ini dan melihat setiap fungsi tersebut.[2] 


\section{METODOLOGI PENELITIAN}

\subsection{Metode Pengumpulan Data}

Dalam penelitian ini untuk mengumpulkan data, penulis melakukan dengan cara observasi, wawancara, analisa dokumen, dan studi pustaka.

a. Observasi

Dalam observasi ini, penulis melakukan pengamatan langsung di Gorilla Gym dengan tujuan untuk mengumpulkan data yang berkaitan dengan adminstrasi membership sebagai data masukan penelitian.

b. Wawancara

Metode ini dilakukan penulis dengan mengajukan pertanyaan yang berhubungan dengan proses administrasi membership secara langsung kepada pimpinan Gorilla Gym. Dari wawancara tersebut, penulis juga mendapatkan dokumen yang akan digunakan dalam pengembangan sistem informasi administrasi membership pusat kebugaran.

c. Analisa Dokumen

Setelah melakukan observasi dan wawancara, penulis mendapatkan dan menganalisa dokumen berjalan pada Gorilla Gym yang berkaitan dengan proses bisnis administrasi membership.

d. Studi Pustaka

Kegiatan ini dilakukan dengan cara membaca jurnal atau prosiding serta referensi lain yang berkaitan dengan administrasi membership pusat kebugaran.

\subsection{Instrumentasi}

Penelitian ini menggunakan teknik wawancara dengan menyiapkan daftar pertanyaan yang akan ditanyakan pada saat wawancara berlangsung. Wawancara dilakukan kepada pemilik terkait administrasi membership di Gorilla Gym untuk memperoleh informasi tentang bagaimana proses administrasi membership di pusat kebugaran.

\subsection{Metode Analisa Data}

Metode analisa data yang digunakan pada penelitian ini menggunakan Activity Diagram[3].

\subsection{Metode Perancangan Sistem}

Metode perancangan sistem informasi[4] menggunakan konsep dan lingkup perancangan yang berorientasi objek, dalam perancangan ini penulis menggunakan tools unified modelling language (UML) yaitu : Use case Diagram [3], Class Diagram[3], Seguence Diagram[3] dan penambahan rancangan layar. Dan untuk implementasi pembuatan program penulis menggunakan pemrograman web PHP dengan Framework Codeigniter[5] dan database MySql.

\section{HASIL DAN PEMBAHASAN}

Adapun hasil dan pembahasan untuk memberikan solusi atas permasalahan yang sudah teridentifikasi sebelumnya akan dijelaskan seperti dibawah ini : 


\subsection{Proses Bisnis dan Activity Diagram Sistem Usulan}

a. Proses Pendaftaran Member

Pada saat pelanggan ingin menjadi member di gorilla gym. Pelanggan mendatangi Staff untuk memberikan data pelanggan, lalu Staff menerima data pelanggan. kemudian melakukan input data, setelah itu pelanggan memilih jenis latihan dan melakukan pembayaran, setelah itu Staff administrasi mencetak kwitansi pembayaran lalu member menerima kwitansi.

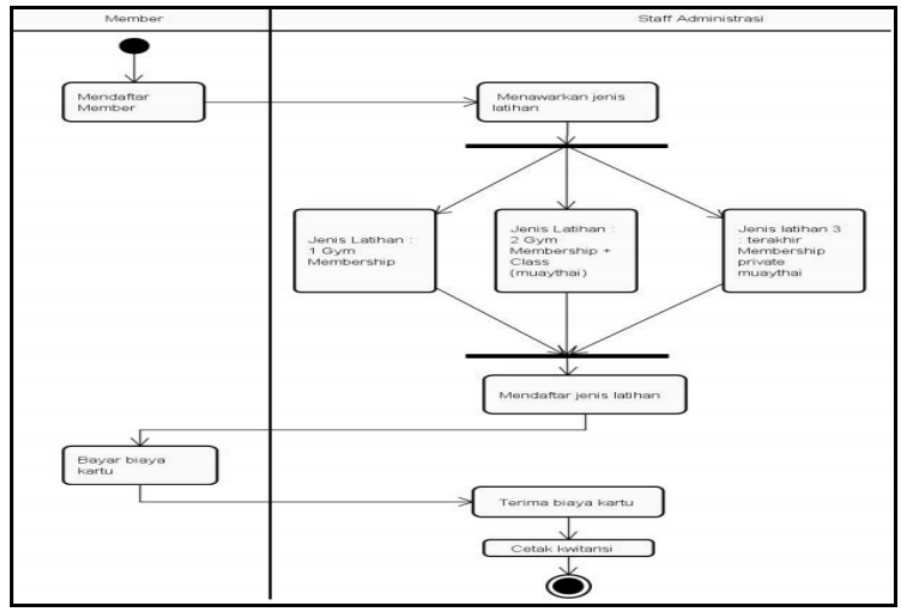

Gambar 1. Activity Diagram Pendaftaran Member

b. Proses Kunjungan Kehadiran

Member yang ingin melakukan kunjungan harus datang ke Staff administrasi untuk memilih jenis kunjungan, Lalu Staff administrasi menginput jenis kunjungan kemudian data akan tersimpan ke dalam database. Jenis kunjungan pertama adalah gym visit perkunjungan, dan yang kedua class visit perkunjungan. lalu member memilih salah satu jenis latihan serta membayar jenis latihan yang telah di tentukan setelah itu member menerima kwitansi pembayaran.

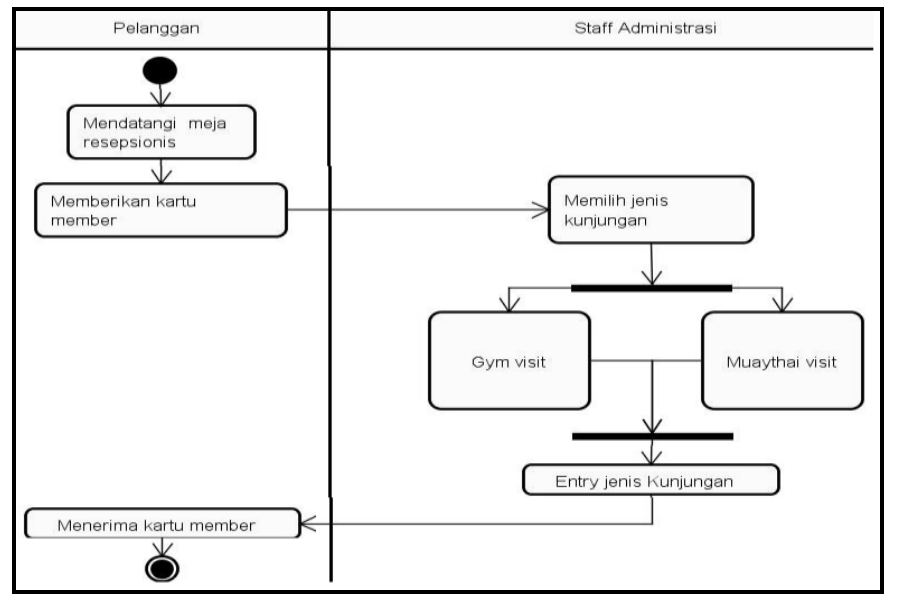

Gambar 2. Activity Diagram Kunjungan Kehadiran 
c. Proses Pendaftaran Program Personal Traineer

Member menuju meja resepsionis untuk meminta informasi program personal traineer lalu Staff administrasi memberikan informasi, setelah itu member memilih personal traineer dan Staff adminsitrasi menginput nomor traineer, lalu member mendapatkan kwitansi dan membayar program personal traineer.

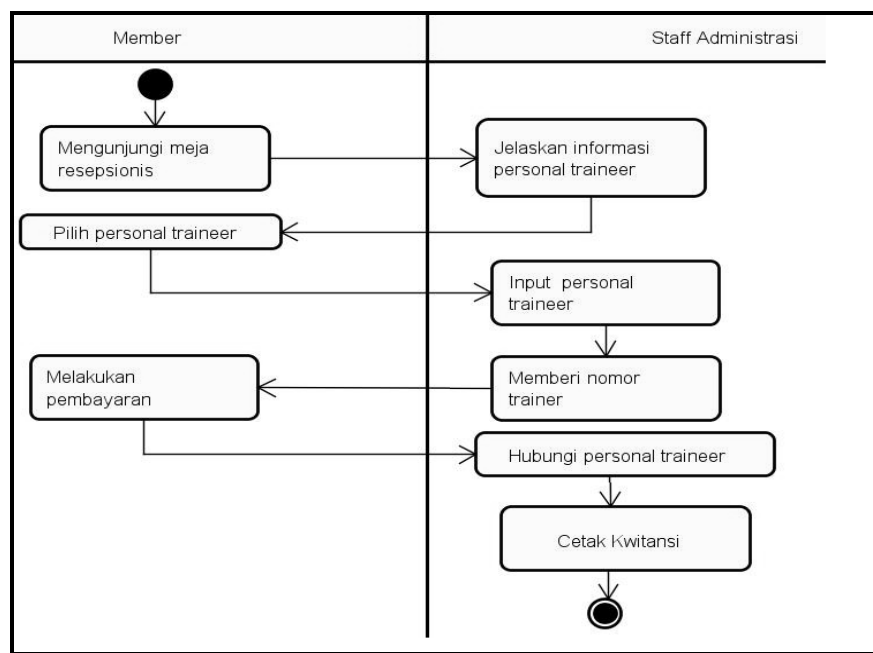

Gambar 3. Activity Diagram Pendaftaran Program Personal Traineer

\subsection{Use Case Diagram}

Untuk perancangan proses sistem informasi administrasi membership dibagi menjadi 3 kelompok yaitu use case diagram master, use case diagram transaksi, dan use case diagram laporan, yang digambarkan dalam bentuk tabel sebagai berikut ini :

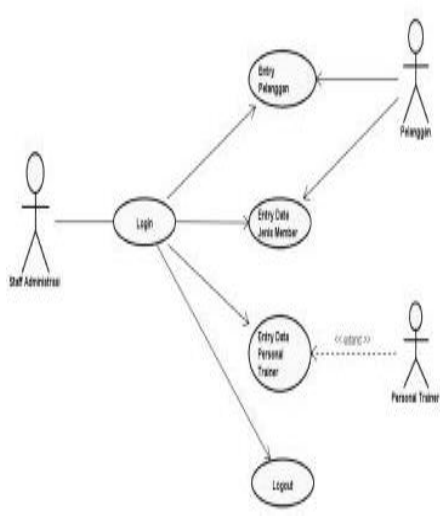

Use Case Diagram Master

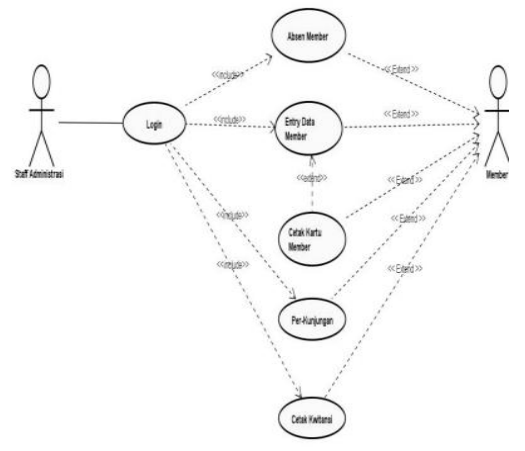

Use Case Diagram Transasksi

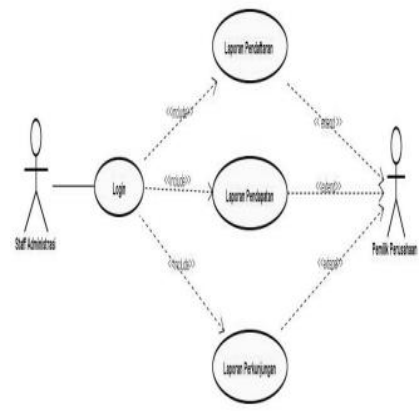

Use Case Diagram Laporan

Gambar 4. Use Case Diagram Administrasi Membership Pusat Kebugaran

\subsection{Class Diagram}

Database atau basisdata adalah kumpulan data yang tersimpan secara sistematis didalam komputer dan dapat diolah atau dimanipulasi menggunakan 
perangkat lunak untuk menghasilkan informasi, adapun bentuk rancangan database proses administrasi membership adalah sebagai berikut :

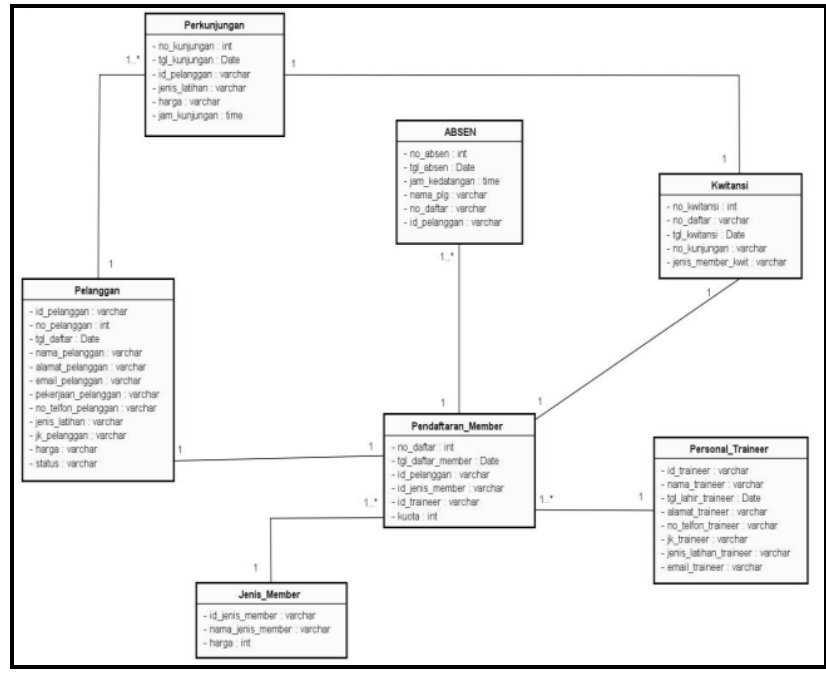

Gambar 5. Class Diagram Administrasi Membership Pusat Kebugaran

\subsection{Rancangan Layar}

Berikut ini beberapa rancangan layar yang terbentuk berdasarkan perancangan proses yang sudah diuraikan diatas untuk pembuatan Sistem Informasi administrasi membership pada pusat kebugaran Gorilla Gym, rancangan layar yang penulis sertakan adalah rancangan layar dashboard, rancangan layar entry pelanggan, rancangan layar kunjungan member dan rancangan layar cetak kwitansi.

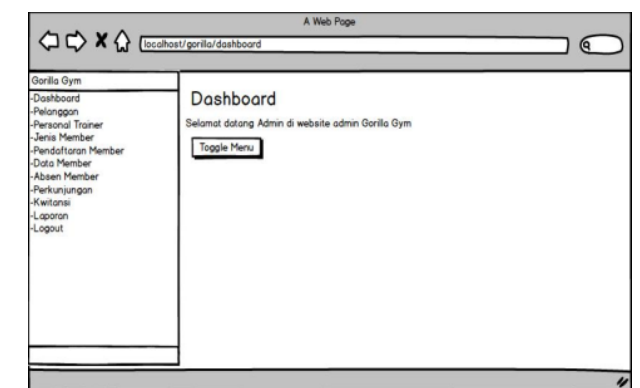

Rancangan Layar Dashboard

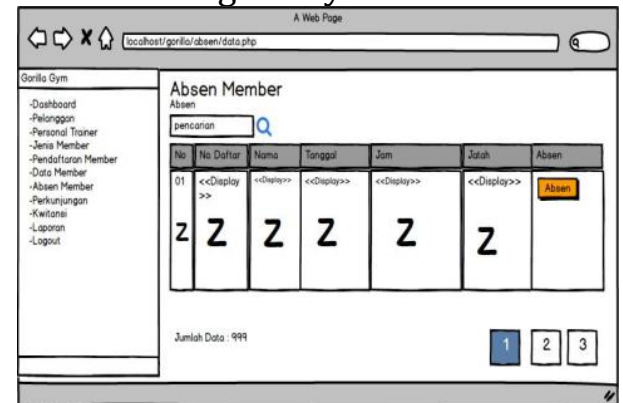

Rancangan Layar Entri Kunjungan Member

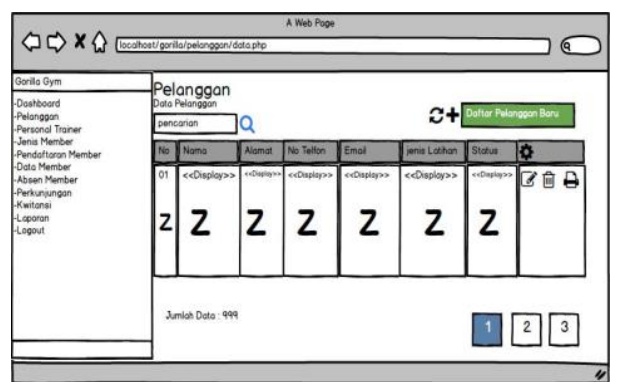

Rancangan Layar Entry Pelanggan

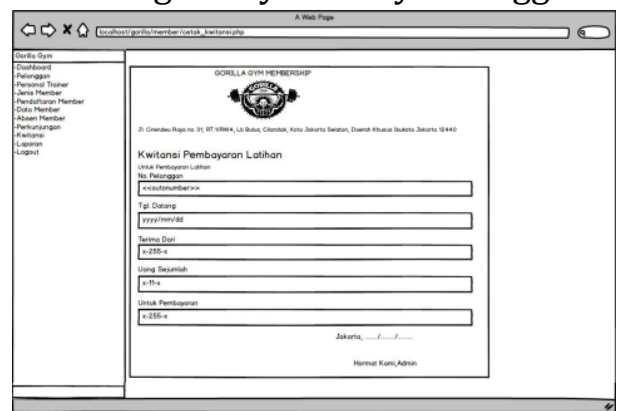

Rancangan Layar Cetak Kwitansi

Gambar 5. Rancangan Layar Sistem Informasi Administrasi Membership 


\section{KESIMPULAN}

Berdasarkan penelitian yang sudah dilakukan untuk memberikan solusi atas permasalahan yang terjadi di Gorilla Gym Jakarta Selatan terkait administrasi membership, maka dapat disimpulkan sebagai berikut :

a. Dengan Adanya sistem informasi Administrasi membership ini, diharapkan mampu mempermudah Staff administrasi dalam membuat laporan bulanan.

b. Dengan adanya sistem informasi Administrasi membership ini, diharapkan mampu membantu mengurangi pemakaian kertas secara berlebihan akibat tidak efisiennya kertas yang banyak di pakai.

c. Dengan Adanya sistem informasi Administrasi membership ini diharapkan dapat membantu Staff administrasi dalam Mencetak Kartu Member yang sering salah dalam penulisannya.

d. Dengan adanya Sistem informasi Administrasi membership ini dapat membantu Staff administrasi dalam menghindari bentrok penjadwalan antara Personal Traineer dan Member.

\section{DAFTAR PUSTAKA}

[1] S. M. Erwanto, Herry, "Rancang Bangun Sistem Informasi Fitness Berbasis Web dan SMS Gateway pada Rajawali Fitness Pekanbaru," J. Sains, Teknol. dan Ind., vol. 14, pp. 72-78, 2016.

[2] A. Widodo, "Perancangan Sistem Informasi Membership PT. Gold Gym," J. IPSIKOM, vol. 3, 2015.

[3] M. and O. Muslihudin, Analisis dan Perancangan Sistem Informasi Menggunakan Model Terstruktur dan UML. Yogyakarta: Penerbit Andi Offset, 2016.

[4] A. Kadir, Pengenalan sistem informasi, Revisi. Yogyakarta: Penerbit Andi Offset, 2016.

[5] S. and Putratama, Pemrograman Web dengan Menggunakan PHP dan Framework Codeigniter. DeePublish, 2016. 